\title{
Periodontal intervention effects on pregnancy outcomes in women with preeclampsia*
}

\author{
Julián A. Herrera, MD¹, Santiago Vélez-Medina, Biol², RodolfoM olano, DDS, MD³, \\ Virna Medina, MD ${ }^{4}$, Javier E. Botero, DDS, PhD 5 , Beatriz Parra, MSc, $P_{h} D^{6}$, \\ ADolfo Contreras, DDS, MSc, PhD ${ }^{7}$
}

\section{SUMMARY}

Objective: To determine the efficacy of periodontal intervention on pregnancy outcome in mild preeclamptic women.

Methods: A sample of 60 pregnant women with mild preeclampsia (blood pressure levels $<160 / 110 \mathrm{~mm}$ and proteinuria $\geq 300 \mathrm{mg} /$ lin 24 hours urine) from the Hospital Universitario del Valle (Cali,Colombia) was included to the study. Preeclamptic women were randomized in two groups, one with periodontal intervention ( $\mathrm{PIG}, \mathrm{N}=28$ ) and another in which the periodontal intervention was practiced after childbirth (NPIG, $\mathrm{N}=32$ ). Maternal socio-demographic, medical and periodontal data were obtained. PIG included patients in which supragingival and subgingival cleaning within ultrasonic and manual devices were performed afterstudy inclusion. The progression from mild to severe preeclampsia, eclampsia orHELLP syndrome, the number of days of clinical stability and the percentile of birth-weight adjusted for gestational age were evaluated in both groups.

Results: Most of the patients (60\%) were multigravids. Gestational age at inclusion was $31.8 \pm 1.6$ weeks. Chronic periodontitis was a frequent finding $(61.7 \%)$. Social, demographic, medical and periodontal conditions were similar between both groups. Disease progression to severe preeclampsia, eclampsia or HELLP syndrome was also similar $89.2 \%$ PIG versus $84.4 \%, \mathrm{p}=0.65)(\mathrm{OR}=1.06 \mathrm{IC} 95 \% 0.87-1.29, \mathrm{p}=0.65)$. Days of clinical stability were similar between the groups (median 10days , range 1-46, PIG versus 12 days, range $1-59, \mathrm{p}=0.57$ ) and the percentile of birth weight adjusted with gestational age had no differences between the groups (median percentil 50 range 5-90 PIG versus percentil 55 range 5-95, $\mathrm{p}=0.73$ ).

Conclusion: Periodontal intervention does not seem to harm the health, the severity or alter the frequency on maternal complications in mild preeclampsia subjects.

Keywords: Preeclampsia; Periodontitis; Periodontal intervention; Pregnancyoutcome; Birth weight; Randomized clinicaltrial.

\section{Eficacia de la intervencion periodontal en el producto del embarazo en mujeres con pre-eclampsia}

\section{RESUMEN}

Objetivo: Determinar la eficacia y seguridad de la intervención periodontal sobre el producto del embarazo en gestantes hospitalizadas con diagnóstico de pre-eclampsia sin complicaciones.

* Project financed by the Instituto Colombiano de Ciencia y Tecnología «(Francisco José de Caldas» (COLCIENCIAS) (Project $N^{\circ} 110604-16325$ ) and Universidad del Valle. Randomized Clinical Trial Latin-American Register:COL83

1. Emeritus Professor, Head Family Medicine Department, Escuela de Medicina, Facultad de Salud, Universidad del Valle, Cali,Colombia.e-mail: herreja@univalle.edu.co

2. Research Assistant, VIREM group, Facultad de Salud, Universidad del Valle, Cali, Colombia. e-mail: santiagovelezm@yahoo.com

3. Facultad de Salud, Universidad del Valle, Cali,Colombia.e-mail: ruddymol07@yahoo.com

4. Auxiliary Professor, Gynecology and Obstetrics Department, Facultad de Salud, Universidad del Valle, Cali, Colombia. e-mail: vpmedinapalmezano@yahoo.com

5. Professor,Periodontal Medicine Group, Escuela de Odontologìa, Universidad de Antioquia, Medellìn, Colombia. e-mail:drjavo@yahoo.com

6. Assistant Professor, Periodontal Medicine Group, Departamento de Microbiologìa, VIREM Group, Facultad de Salud, Universidad del Valle,Cali,Colombia.e-mail:bparrap@yahoo.com

7. Professor, School of Odontology. Periodontal Medicine Group, Vice-Dean of Research, Facultad de Salud, Universidad del Valle,Cali,Colombia.e-mail:adolfoco@yahoo.com

Received for publication January 31, 2008 Accepted for publication April 14, 2009 
Métodos: En un ensayo clínico controlado se evaluaron 60 mujeres embarazadas con diagnóstico de pre-eclampsia leve (presión arterial $<160 / 110 \mathrm{~mm} \mathrm{Hg}$ y proteinuria $\geq 300 \mathrm{mg}$ / 1 en orina de 24 horas), que se trataron en la unidad de alto riesgo obstétrico del Hospital Universitario del Valle (Cali, Colombia). Se evaluaron las características socio-demográficas, así como los aspectos médicos y periodontales. De este conjunto $28(46.7 \%)$ gestantes se incluyeron al azar en el grupo con intervención periodontal anteparto (GIP) y 32 $(53.3 \%)$ en el grupo sin intervención periodontal (GNIP). El análisis se hizo de acuerdo con la intención de tratamiento. La variable dependiente fue la proporción de mujeres que agravaron su condición pre-eclámpticahacia pre-eclampsia severa, eclampsia o síndrome de HELLP, el número de días de estabilidad clínica y el percentil de peso del recién nacido ajustado para la edad de la gestación.

Resultados: De las pacientes $60 \%$ eran multíparas. La edad gestacional promedio de ingreso al estudio fue 31.8 semanas. El diagnóstico periodontal más frecuente fue periodontitis crónica (61.7\%). Las características socio-demográficas, obstétricas y periodontales fueron afines en ambos grupos. La pre-eclampsia se agravó de manera comparable en los dos grupos (GIP 89.2\% versus GNIP 84.4\%, $\mathrm{p}=0.65)(\mathrm{OR}=1.06 \mathrm{IC} 95 \%$ 0.87-1.29, $\mathrm{p}=0.65)$. La estabilidad clínica en días, fue parecida en ambos grupos (GIP mediana 10 días, rango 1-46 versus GNIP 12 días, rango 1-59, $\mathrm{p}=0.57$ ). La mediana del peso del recién nacido ajustado por la edad gestacional fue semejante en los dos grupos (GIP percentil 50, rango 5-90 versus GNIP percentil 53 rango 5-95, $\mathrm{p}=0.73$ ).

Conclusiones: El tratamientoperiodontal en mujeres con pre-eclampsia no complicada no incrementa la severidad o frecuencia de las complicaciones maternas.

Palabras clave: Pre-eclampsia; Intervención periodontal; productodel embarazo; Peso reciénnacido; Ensayo clínico aleatorio controlado.

Preeclampsia (PE) is an exclusive illness of human gestation. It contributes with $42 \%$ of maternal and perinatal mortality, and is the first cause of intrauterine growth restriction, preterm birth, and low weight at birth $^{1}$. It is known as a «the disease of several theories» because the aetiology is still unknown although some risk factors have been identified such as: first pregnancy/ null parity, chronic kidney disease, uterine malformations, none prenatal care, diabetes, familial predisposition, obesity, hypertension, low social-economical level, or non treated infections ${ }^{2}$.

Endothelial dysfunction in preeclampsia is a constant event, but it is unknown if this dysfunction is cause or consequence of the illness. In pregnancy there is an inflammatory physiological state which is more accentuated in pregnant women developing preeclampsia, and has been associated to increased levels of proinflammatory cytokines(IL-6, TNF-? , reactive C protein) ${ }^{3,4}$ and infections ${ }^{5}$, including periodontitis ${ }^{6,7}$. Changes have been observed in atherosclerosis at placental level in pregnant women with preeclampsia as well as bacterial translocation of oral pathogens to placenta ${ }^{8}$. Also, it was recently demonstrated that periodontal illness is related to increased levels of reactive $\mathrm{C}$ protein specifically in women with preeclampsia ${ }^{3}$.

Besides, a controlled clinical trial including males and none pregnant females demonstrated that periodontal treatment improves endothelial disfunction ${ }^{9}$. This may have implications on preeclampsia, since vascular stress generates vasoconstriction and platelet activation worsening the preeclampsia clinical course.

A preliminary study determined the effect of periodontal intervention on pregnant women with preterm birth risk factors, which had decreased incidence of this event $^{10,11}$, however, when intervention is done late there is no significant benefit ${ }^{12}$. Since preeclampsia is both associated and principal cause of induced preterm birth, the aim of this study was to evaluate periodontal intervention efficacy and safety on pregnancy outcome of women diagnosed with mild preeclampsia.

\section{MATERIALS AND METHODS}

A randomized controlled clinic trial was performed between March 2006 and December 2007, including 60 pregnant women hospitalized in the Obstetric High Risk Unit at Hospital Universitario del Valle (HUV), Cali, Colombia. The study was estimated with $?=0.1$ and $?=0.2$, one case by one control, complication expected frequency of $80 \%$ (progression to severe preeclampsia, eclampsia, HELLP syndrome, or maternal fetal complications). Expected risk reduction due to periodontal intervention was taken into account in preterm birth studies and low weight at birth ${ }^{10,11}$ as this is the first research in which periodontal intervention is performed to preeclampsia patients. Sample size was estimated in 60 patients. Pregnant women diagnosed with mild preeclampsia and gestational age between 26 and 34 weeks were the inclusion criteria, without caring on parity, or patient age. 
Gestational age was calculated based on a trustable amenorrhea if this existed (regular menstrual cycle before pregnancy, null anovulatories use), or echography on first pregnancy trimester.

This study was approved by two Institutional Ethics Committees (Facultad de Salud, Universidad del Valle and HUV). Patients agree or accept voluntary participation in research. Exclusion criteria were: pregnant women with history of chronic hypertension, kidney or cardiovascular disease previous to pregnancy, diabetes or past history of infections different to periodontal or human immunodeficiency virus (HIV).

Included patients were randomized by blocks to avoid disparity in groups, in case of suspension of the study (severe adverse effects of periodontal treatment). Treatment intention was determined at random, in closed envelopes prepared by professionals external to the research group. Of the patients $28(47 \%)$ were randomized to the periodontal intervention group (PIG, conventional medical treatment with periodontal treatment at day of inclusion) and 32 (53\%) were randomized to the group without periodontal intervention (NPIG, conventional medical treatment, and periodontal treatment postpartum for ethical reasons). Patients were healthy before developing preeclampsia. Other data like educational level, smoking habits, and alcoholism, were obtained from clinic record and confirmed by interview. Patients had not received antibiotics or periodontal treatment 3 and 6 months before inclusion, respectively.

Preeclampsia's clinic diagnosis was done by attending doctors and confirmed by research group's gynaecologists and obstetricians, and was defined as pregnancy induced hypertension of $\geq 140 / 90 \mathrm{~mm} / \mathrm{Hg}$ sitting down (confirmed with 2 tests separated by 4 hours each) and proteinuria $\geq 300 \mathrm{mgin} 24$ hoursurine, without concomitant urine infection.

Mild preeclampsia diagnosis was defined when patient had systolic blood pressure between 140-160 $\mathrm{mm} / \mathrm{Hg}$ and/ordiastolic between $90-110 \mathrm{~mm} / \mathrm{Hg}$, without pre-convulsive symptoms (headache, blurred vision, epigastralgia, phosphene, tinnitus, normal osteo-tendinous reflex) and with no compromise of target organs (altered LFTs, altered LDH, thrombocytopenia) or fetal compromise (IGRU or oligohydramnios).

Number of teeth and periodontal clinical parameters were measured on every patient. Third molars were excluded from evaluation since eruption is not proper and interfere with measurements. All measurements were practiced by trained periodontists with the same evaluation criteria and equipment. Measurements were registered on a periodontics chart and periodontal diagnosis was confirmed by a second group of periodontists (JB, JS). Periodontists did not know the objectives of the research. Every tooth was evaluated to determine pocket depth $(\mathrm{mm})$ and clinical attachment level (mm, six measurements per tooth -mesiobuccal, buccal, distobuccal, mesiolingual, lingual and distolingual using a periodontal probe UNC-Hu-Friedy). Pocket depth was determined measuring the distance between gingival margin to the bottom of periodontal pocket. Clinical attachment level was determined by measuring the distance between enamel-cemental line to the bottom of periodontal pocket. Gingival bleeding was determined on the same six sites, and was registered as positive if occurred 15 seconds after the periodontal probing. Bleeding at probing was determined as a percentage of the bleeding sites. Periodontal diagnosis was establish according to the report consensus criteria of the American Academy of Periodontology ${ }^{13}$. Dependent variable at medical assessment was outcome of pregnancy characterized by number of events of preeclampsia, eclampsia, or HELLP's syndrome developed, new born percentile weight adjusted to gestational age and number of complete days of clinic stability after study inclusion. Independent variable was patients group (PIG or NPIG). Confusion variables were social and demographic variables. Periodontal treatment included oral health education, hygiene, dental plaque removal, scaling and root planning (if necessary), subgingival irrigation without antibiotic administration in one single session (one to two hours). Periodontal treatment was performed by periodontists.

\section{STATISTICAL ANALYSIS}

Statistical analysis was performed using univariate analysis to evaluate sample characteristics in both groups with measures of central tendency and dispersion. Bivariate analysis was performed to evaluate periodontal treatment effect on pregnancy outcome. Differences between continue variables were evaluated using Student's t test (two tailed) for data with normal distribution, and Kruskal-Wallis' test for data with other 


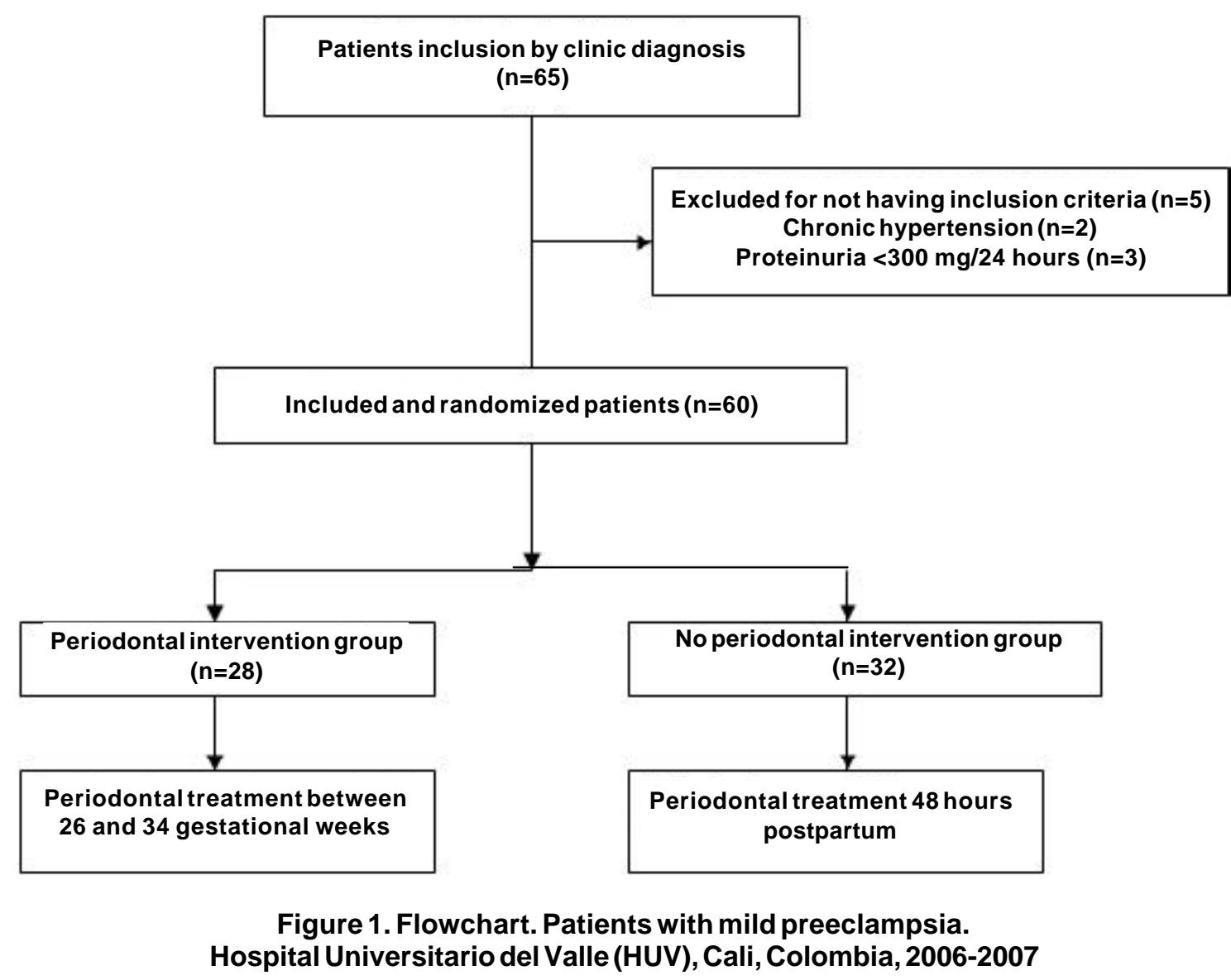

type of distribution. $?^{2}$ or Fischer exact test (if the smallest value was under 5) was used to analyze differences in categorical variables.

Analysis was performed with EPIINFO 6.0 (CDC, Atlanta) and Epistat 3.0 (Richardson, Texas, USA). $\mathrm{p}<0.05$ was consider significant.

\section{RESULTS}

Sixty five patients were identified of having mild preeclampsia and invited to participate in the study. Afterwards 5 patients were excluded, $3(4,6 \%)$ that having a presumptive clinic diagnose of mild preeclampsia, also had less proteinuria $<300 \mathrm{mg} / \mathrm{dl}$ in 24 hours urine, which locates them as gestational hypertension; and $2(3,1 \%)$ for whom was determined that hypertension condition corresponded to a chronic disease (Figure 1).

Mean age of patients included was $24.7 \pm 6.4$ years and gestational age at entry of 31,8 weeks. Most of them $(60 \%)$ were multiparae and had low socioeconomic level (83\%, strata 1-2, ranks 1-6, National Administrative Department of Statistics classification DANE). Most frequent marital status was unmarried in law (60\%), predominant race was mixed in ethnic backgrounds and urban procedence (Table 1). Obstetric sociodemographic (Table 1) and periodontal clinic characteristics (Table 2) were similar in both groups, except for age, where patients in PIG were younger than patients from the NPIG (24 \pm 6.5 years PIG vs. $27 \pm 7.6$ years NPIG, $\mathrm{p}=0.01$ ). Other difference found was mean gestational week at inclusion time (31.2\% for PIG and 32.4\% for NPIG, $\mathrm{p}=0.04$ ). Patients did not inform of smoking or drinking habits. Most frequent periodontal diagnose was chronic periodontitis $(61,7 \%)$ (Table 2). Patient belonging to PIG presented more mild chronic periodontitis when compared to NPIG (57\% PIG vs. 37\% NPIG) $(\mathrm{p}=0.001)$ (Table 2). 
Table 1

Socio-demographic and obstetric characteristics of women suffering mild preeclampsia included in the study. Hospital Universitario del Valle (HUV), Cali, Colombia, 2006-2007

\begin{tabular}{|c|c|c|c|}
\hline Variable & PIG (n=28) & NPIG (n=32) & $\mathbf{p}$ \\
\hline Age $(X \pm D E)$ & $24 \pm 6.5$ & $27 \pm 7.6$ & 0.01 \\
\hline \multicolumn{4}{|l|}{ Parity (n/\%) } \\
\hline Primiparous & $12(43)$ & $8(25)$ & 0.09 \\
\hline Multiparous & $16(57)$ & $20(63)$ & 0.36 \\
\hline Grand multiparous ( $\geq$ G5) & 0 & $4(13)$ & 0.26 \\
\hline Weeks of gestation inclusion & 31.2 & 32.4 & 0.04 \\
\hline \multicolumn{4}{|l|}{$\operatorname{Race}(\mathrm{n} / \%)$} \\
\hline Mixed ethnic backgrounds & $17(61)$ & $20(63)$ & \multirow{3}{*}{0.73} \\
\hline Black & $10(36)$ & $11(34)$ & \\
\hline Indigenous & $1(3.6)$ & $1(3)$ & \\
\hline \multicolumn{4}{|l|}{ Marital status(n/\%) } \\
\hline Single & $7(25)$ & $7(22)$ & \multirow{3}{*}{0.53} \\
\hline Unmarried in law & $18(64)$ & $19(59)$ & \\
\hline Married & $3(11)$ & $6(19)$ & \\
\hline \multicolumn{4}{|l|}{ Socioeconomic level(n/\%) } \\
\hline Stratum 1 (range 1-6) & $9(32)$ & $10(31)$ & \multirow{3}{*}{0.93} \\
\hline Stratum 2 (range 1-6) & $15(54)$ & $16(50)$ & \\
\hline Stratum 3 (range 1-6) & $4(14)$ & $6(19)$ & \\
\hline \multicolumn{4}{|l|}{ Educational level (n/\%) } \\
\hline Iliterate & $1(4)$ & $1(3)$ & \multirow{5}{*}{0.43} \\
\hline Basic education & $6(21)$ & $10(31)$ & \\
\hline Secondary education & $21(75)$ & $19(59)$ & \\
\hline Technical education & 0 & $2(6)$ & \\
\hline University & 0 & 0 & \\
\hline \multicolumn{3}{|l|}{ Residence (n/\%) } & \multirow{3}{*}{0.18} \\
\hline Urban & $21(75)$ & $29(91)$ & \\
\hline Rural & $7(25)$ & $3(9)$ & \\
\hline
\end{tabular}

Differences between continue variables were detected with a two tailed T test and Kruskall-Wallis test, and between categorical variables with ? $?^{2}$ and Fisher's test

Twenty two $(78,6 \%)$ of the patients included in the PIG worsen their preeclamptic condition to severe preeclampsia, eclampsia, HELLP syndrome (hemolysis, liver enzyme rising, platelets consumption), or another kind of complication, while for the NPIG $(56,3 \%)$ were eighteen patients $(\mathrm{p}=0.07)(\mathrm{OR}=2.85$, IC 95\%, 0.918.92). Clinic stability was similar for both groups; for PIG was 10 days (ranging 1-46 days), while for NPIG was 12 days (ranging $1-59$ days) $(\mathrm{p}=0.57)$. Preterm birth incidence was similar for both groups (PIG 26, 92,8\% vs. NPIG $24,7 \%, \mathrm{p}=0,06)$. For PIG, $9(32,1 \%)$ of the new born needed neonatal intensive care unit (ICU) due to some complication, in contrast, $5(15,6 \%)$ of the new born from the NPIG needed ICU ( $\mathrm{p}=0.13)$.

Neonates weight percentiles adjusted to gestational age were similar for both groups (PIG 50, rank 5-90vs. NPIG 53, rank 5-95, p=0,73) (Table 3). Twenty-one of the patients $(75 \%)$ included in the PIG presented some 
Table 2

Periodontal clinical characteristics of pregnant women with mild preeclampsia by periodontal intervention groups. Hospital Universitario del Valle (HUV), Cali, Colombia, 2006-2007

\begin{tabular}{lccc}
\hline \multicolumn{1}{c}{ Variable } & PIG $(\mathbf{n}=\mathbf{2 8})$ & NPIG (n= 32) & p \\
\hline Diagnosis(n/\%) & & & \\
\hline Gingivitis & $11(39)$ & $14(44)$ & 0.61 \\
Chronic slight periodontitis & $16(57)$ & $12(37)$ & 0.00 \\
\hline Chronic moderate periodontitis & $1(4)$ & $5(17)$ & 0.25 \\
Chronic severe periodontitis & 0 & $1(3)$ & \\
\hline
\end{tabular}

60 patients were analyzed after exclusion

Table 3

Maternal complications post-periodontal treatment and new born weight from women with mild preeclampsia

\begin{tabular}{lccc|}
\hline \multicolumn{1}{c}{ Variable } & PIG (n=28) & NPIG (n=32) & p \\
\hline None & 7 & 14 & 0.12 \\
Severepreeclampsia & 17 & 16 & 0.40 \\
\hline HELLP syndrome & 1 & 0 & 0.41 \\
Other type of complication & 3 & 2 & 0.53 \\
\hline New born weight adjusted to gestational & $50(5-90)$ & $53(5-95)$ & 0.73 \\
age (percentile) (mean and range) & & & \\
\hline
\end{tabular}

kind of clinic complication during pregnancy, $17(60,7 \%)$ patients developed severe preeclampsia, one $(3,6 \%)$ developed HELLP's syndrome, and three $(10,7 \%)$ had some other kind of complication like premature rupture of membranes, oligohydramnios and polihydramnios, while 7 of this patients $(25 \%)$ did not present any other complication during pregnancy, after being include in the research. For the NPIG, 18 patients $(56,3 \%)$ presented complications during pregnancy, after being included in the research, $16(50 \%)$ presented severe preeclampsia, $2(6,3 \%)$ presented some kind of complication, respiratory and uteroplacental failure, and $14(43,8 \%)$ of them did not developed any complication (Table 3). Comparing statistically this results, there is no significant difference between PIG and NPIG ( $p=0,67)$, indicating that periodontal treatment was not associated with development of maternal clinical complications in women suffering mild preeclampsia.

\section{DISCUSSION}

Preeclampsia is characterized by a systemic vascular dysfunction that affects placental circulation, as demonstrated by histopathology changes. Indeed of been considered a multifactorial illness, there is growing evidence of the presence of chronic infection ${ }^{2}$ as etiological/or triggering factor for systemic vascular dysfunction (endothelial dysfunction). Previous studies observed an association between periodontal illnesses and preeclampsia ${ }^{3,6,14-17}$. Studies about the effect of periodontal intervention on pregnant women suffering preeclampsia are not reported in literature, however, diverse studies exist relating periodontal illness and adverse outcome of pregnancy in what concerns to low weight at birth, preterm birth, intrauterine growth restriction, low gestational age, and gestational diabetes ${ }^{18}$. Literature reports four studies about association 
between periodontal illness and preeclampsia ( 3 casecontrol studies, and one prospective study), with ORs from 2.4 and 3.5, however, a case-control study carried out in Argentina did not found association to an adjusted OR 0.99 (IC 0.70-1.40) ${ }^{4}$.

A recent meta-analysis determined that urinary infection ( $\mathrm{N}=104,927 \mathrm{OR}=1.63$ IC 95\% 1.43-1.83) and periodontal illness $(\mathrm{N}=3,507 \mathrm{OR}=1.76$ IC $95 \% 1.39$ $2.17)^{1}$ are unique infections associated to preeclampsia development.

For ethical reasons, and taking into account that preeclampsia is a serious and potentially fatal disease, and treatment consists on patient's stabilization while pregnancy ends, were only included pregnant women diagnosed with mild preeclampsia. None patients with severe preeclampsia were included since pregnancy on this patients ends in 24-48 hours ${ }^{1}$ post diagnosis. Inclusion of these patients allowed following clinical evolution to determine periodontal intervention effect on women suffering preeclampsia.

The present controlled clinic assay determined that severity and frequency of medical complications in mild preeclampsia are not significantly increased after periodontal intervention (Table 3). Mean new born weight was lower in PIG due to gestational age at birth since weight percentile adjusted to gestational age were similar within groups (Table 3). As observed in a previous study on patients with preterm birth and periodontal intervention, this did not modify illness course within groups and was equally safe $\mathrm{se}^{12,20}$.

Socio-demographic, obstetric, and periodontal characteristics were similar in both groups, except the variable chronologic and gestational age, which demonstrates that population group selected was relatively homogeneous due to study randomization (Tables 1,2). Preeclampsia occurs generally on patients at extreme reproductive age, young women, or older than 35 years, which could influence the bigger number of older women on a group affecting mean age in each group. Since extreme reproductive age is a risk variable once complications happened, age as an independent variable has not a direct effect on pregnancy outcome.

Periodontal illness is associated to increase risk of gestation adverse outcome. Thus, confirmation of periodontal illness as an independent risk factor for adverse outcomes must be taken into account for an integral evaluation of pregnant women since is a preventable and treatable illness, in contrast with preeclampsia, which is a treatable but difficult to prevent. Studies with larger groups are necessary to evaluate the efficacy of early periodontal intervention during pregnancy in relation with endothelial dysfunction and preeclampsia development.

Anew born resulting from a complicated preeclamptic pregnancy increases to $50 \%$ probability of using neonatal ICU, just for the fact of suffering this illness $(\mathrm{OR}=1.50$ IC 95\% 1.2-2.0). The present study does not present differences related to maternal morbidity in the PIG in relation with periodontal intervention postpartum (NPIG) and overall impact of periodontal intervention did not have a negative effect on new born health when evaluated with level of neonatal ICU use, what allow us to conclude that periodontal intervention in patients suffering mild preeclampsia does not increase risks to the mother or fetus, being a safe procedure.

It is known that periodontitis occurs in at least $60 \%$ of pregnant women with low socioeconomic level. Its presence increases C-reactive protein in pregnant women ${ }^{3}$, one of the ways to endothelial dysfunction. Pregnant women that develop preeclampsia present an early endothelial dysfunction in pregnancy ${ }^{4}$. It is known that periodontitis reduces endothelial funtion ${ }^{10}$. According to this, it is logic to think that periodontal intervention would have a better preventive effect when this risk factor is interfered in early stages of pregnancy.

Previously was established that periodontitis treatment during pregnancy is safe ${ }^{19}$ as it is for pregnant women with preterm birth ${ }^{12,20}$ and according with the results of the present study, this conclusion expands to pregnant women that suffer mild preeclampsia. Knowing that periodontal treatment does not modify preeclampsia course, it would be important to determine the effect of early periodontal intervention on normotensive pregnant women with high risk of preeclampsia. Endothelial dysfunction is a constant in preeclampsia pathogenesis, it is interesting to remember that periodontal treatment improves endothelial function in patients with periodontitis $^{9}$.

\section{ACKNOWLEDGMENTS}

To doctors Javier Fonseca and Freddy Briceño from Gynecology and Obstetrics Department for contributions to study design and construction of randomization tables, 
doctor Hoover Canaval manager of Gynecology and Obstetrics Department of HUV for his valuable collaboration. To doctors Jorge E. Soto, Roger Mauricio Arce, and residents of periodontics Lilian Gómez, Juliana Vivas, Johanna Delgado, Viviana González, Beatriz Ramírez, Ana María Londoño, Liliana Vera, Isabel Cristina Silva and Angélica Salcedo for readiness to comply with periodontal evaluation of patients.

\section{REFERENCES}

1. Conde-Agudelo A, Villar J, Lindheimer M. Maternal infection and risk of preeclampsia: systematic review and metaanalysis. Am J Obstet Gynecol. 2008; 198: 7-22.

2. Herrera JA, Chaudhuri G, López-Jaramillo P. Is infection a major risk factor for preeclampsia? Med Hypotheses. 2001; 57: 393-7.

3. Herrera JA, Parra B, Herrera E, Botero JE, Arce RM, Contreras A, et al. Periodontal disease severity is related to high levels of C-reactive protein in pre-eclampsia. J Hypertens. 2007; 25: 1459-64.

4. García RG, Celedón J, Sierra-Laguado J, Alarcón MA, Luengas $\mathrm{C}$, Silva F, et al. Raised C-reactive protein and impaired flowmediated vasodilation precede the development of preeclampsia. Am J Hypertens. 2007; 20:98-103.

5. León R, Silva N, Ovalle A, Chaparro A, Ahumada A, Gajardo $\mathrm{M}$, etal. Detection of Porphyromonas gingivalis in the amniotic fluid in pregnant women with a diagnosis of threatened premature labor. J Periodontol. 2007; 78: 1249-55.

6. Contreras A, Herrera JA, Soto JE, Arce RM, Jaramillo A, Botero JE. Periodontitis is associated with preeclampsia in pregnant women. JPeriodontol. 2006; 77: 182-8.

7. Jeffcoat MK, Geurs NC, Reddy MS, Cliver SP, Goldenberg RL, Hauth JC. Periodontal infection and preterm birth: results of a prospective study. J Am Dent Assoc. 2001;132: 875-80.

8. Barak S, Oettinger-Barak O, Machtei EE, Sprecher H, Ohel G. Evidence of periopathogenic microorganisms in placentas of women with preeclampsia. JPeriodontol. 2007; 78: 670-6.
9. Tonetti MS, D'Aiuto F, Nibali L, Donald A, Storry C, Parkar $\mathrm{M}$, et al. Treatment of periodontitis and endothelial function. NEngl J Med. 2007; 356:911-20.

10. López NJ, Smith PC, Gutiérrez J. Periodontal therapy may reduce the risk of preterm low birth weight in women with periodontal disease: a randomized controlled trial.JPeriodontol. 2002; 73: 911-24.

11. López NJ, Da Silva I, Ipinza J, Gutiérrez J. Periodontal therapy reduces the rate of preterm low birth weight in women with pregnancy-associated gingivitis. JPeriodontol. 2005; 76: 214453.

12. Xiong X, Buekens P, Vastardis S, Yu SM. Periodontal disease and pregnancy outcomes: state-of-the-science. ObstetGynecol Surv. 2007; 62:605-15.

13. International Workshop for a Classification of Periodontal Diseases and Conditions. Ann Periodontol. 1999; 4: 1-112.

14. Canakci V, Canakci CF, Canakci H, Canakci E, Cicek Y, Ingec $\mathrm{M}$, et al. Periodontal disease as a risk factor for pre-eclampsia: a case control study. Aust NZJObstet Gynaecol. 2004; 44: 56873.

15. Canakci V, Canakci CF, Yildirim A, Ingec M, Eltas A, Erturk A. Periodontal disease increases the risk of severe pre-eclampsia among pregnant women.J Clin Periodontol. 2007; 34: 63945.

16. Oettinger-Barak O, Barak S, Ohel G, Oettinger M, Kreutzer H, Peled M, etal. Severe pregnancy complication (preeclampsia) is associated with greater periodontal destruction.JPeriodontol. 2005; 76: 134-7.

17. Boggess KA, Lieff S, Murtha AP, Moss K, Beck J, Offenbacher $\mathrm{S}$. Maternal periodontal disease is associated with an increased risk for preeclampsia. Obstet Gynecol. 2003; 101:227-31.

18. Xiong X, Buekens P, Fraser WD, Beck J, Offenbacher S. Periodontal disease and adverse pregnancy outcomes: a systematic review. BJOG. 2006; 113:135-43.

19. Offenbacher S, Lin D, Strauss R, McKaig R, Irving J, Barros $\mathrm{SP}$, et al. Effects of periodontal therapy during pregnancy on periodontal status, biologic parameters, and pregnancy outcomes: a pilot study. J Periodontol. 2006; 77: 2011-24.

20. López R. Periodontal treatment in pregnant women improves periodontal disease but does not alter rates of preterm birth. Evid Based Dent. 2007; 8: 38. 